\title{
Effect of phosphate and temperature on force exerted by white muscle fibres from dogfish
}

\author{
S.-J. Park-Holohan $\cdot$ T. G. West $\cdot$ R. C. Woledge $\cdot$ \\ M. A. Ferenczi • C. J. Barclay • N. A. Curtin
}

Received: 28 April 2009/Accepted: 1 January 2010/Published online: 19 January 2010

(c) The Author(s) 2010. This article is published with open access at Springerlink.com

\begin{abstract}
Effects of Pi (inorganic phosphate) are relevant to the in vivo function of muscle because $\mathrm{Pi}$ is one of the products of ATP hydrolysis by actomyosin and by the sarcoplasmic reticulum $\mathrm{Ca}^{2+}$ pump. We have measured the Pi sensitivity of force produced by permeabilized muscle fibres from dogfish (Scyliorhinus canicula) and rabbit. The activation conditions for dogfish fibres were crucial: fibres activated from the relaxed state at 5,12 , and $20^{\circ} \mathrm{C}$ were sensitive to $\mathrm{Pi}$, whereas fibres activated from rigor at $12^{\circ} \mathrm{C}$ were insensitive to $\mathrm{Pi}$ in the range 5-25 $\mathrm{mmol} \mathrm{l}^{-1}$. Rabbit fibres activated from rigor were sensitive to Pi. Pi sensitivity of force produced by dogfish fibres activated from the relaxed state was greater below normal body temperature $\left(12^{\circ} \mathrm{C}\right.$ for dogfish) in agreement with what is known for other species. The force-temperature relationship for dogfish fibres (intact and permeabilized fibres activated from relaxed) showed that at $12^{\circ} \mathrm{C}$, normal body temperature, the force was near to its maximum value.
\end{abstract}

Keywords Phosphate - Temperature ·

Permeabilized muscle $\cdot$ Force

S.-J. Park-Holohan · T. G. West · R. C. Woledge ·

M. A. Ferenczi - N. A. Curtin $(\bowtie)$

Molecular Medicine Section, National Heart and Lung Institute,

Sir Alexander Fleming Building, Imperial College London,

London SW7 2AZ, UK

e-mail: n.curtin@imperial.ac.uk

C. J. Barclay

School of Physiotherapy \& Exercise Science, Gold Coast

Campus, Griffith University, Queensland 4222, Australia

\section{Introduction}

Intact muscle fibres from dogfish have been used to investigate the mechanics and energetics of contractions that mimic in vivo performance (Curtin and Woledge 1991, 1993a, b, 1996; Lou et al. 1997, 1998a, b, c, 1999, 2000, 2002a, b; Curtin et al. 1997, 1998). Our experiments on intact and permeabilized dogfish fibres give data on force production, turnover of both the physical energy (heat and mechanical work) by intact fibres, and chemical energy (from ATP hydrolysis) during isometric contraction (West et al. 2004). A kinetic model of the crossbridge cycle was devised that accounted for the main features of the results from both intact and permeabilized fibres including time courses of force production and inorganic phosphate $(\mathrm{Pi})$ produced by the actomyosin (AM) ATPase. This evidence suggested that force production by intact and permeabilized dogfish fibres is rather insensitive to [Pi], which contrasts with the extensive body of evidence from experiments on muscle fibres from other animals (Brandt et al. 1982; Altringham and Johnston 1985; Brozovich et al. 1988; Cooke et al. 1988; Godt and Nosek 1989; Pate and Cooke 1989; Dantzig et al. 1992; Pate et al. 1998; Coupland et al. 2001; Debold et al. 2004, 2006; Caremani et al. 2008), and is believed to be due to shifting some of the actomyosin product complex (AM.ADP.Pi) from a high force to a low force state(s). See the recent review by Cooke (2007). This raises the question of whether dogfish fibres are genuinely different from those of other species, or whether some aspect of our experimental conditions caused the dogfish fibres to be insensitive to Pi. Thus we have directly tested the effect of $\mathrm{Pi}$ on force using the usual protocol for such experiments $\left(\mathrm{Ca}^{2+}\right.$ activate from relaxed) at a range of temperatures, and also using an activation protocol in which, like that used by West et al. (2004), the 
fibre is activated from the rigor state. The effect of temperature on force produced by intact fibres from dogfish was also tested.

\section{Materials and methods}

Dogfish

Dogfish (Scyliorhinus canicula, L.) were maintained in re-circulated artificial seawater at $12^{\circ} \mathrm{C}$, the temperature of the natural environment for dogfish, and fed chopped mackerel. Fish were held in a cylindrical aquarium (1,000 1) subjected to 12-h light: 12-h dark cycle. The fish were killed by a blow to the head followed by destruction of the brain and spinal cord in accordance with Schedule 1 of the UK Animals (Scientific Procedures) Act 1986. Slices of white muscles were removed (2-4 mm thick, 100-200 $\mathrm{mm}^{2}$ ) from the myotomes located immediately posterior to the visceral cavity. The slices were stored at $5^{\circ} \mathrm{C}$ in saline containing (mmol l${ }^{-1}$ ): $\mathrm{NaCl}, 292 ; \mathrm{KCl}, 3.2 ; \mathrm{MgSO}_{4}, 1.0$; $\mathrm{Na}_{2} \mathrm{SO}_{4}, 1.6 ; \mathrm{NaHCO}_{3}, 5.9 ; \mathrm{CaCl}_{2}, 5.0$; urea, 483; and $1.5 \mathrm{mg}^{-1}$ of tubocurarine.

\section{Intact fibres}

Four fibre bundles were used to measure the effect of temperature $\left(2-20^{\circ} \mathrm{C}\right)$ on isometric tetanus force. The methods were similar to those used previously (Lou et al. 2002b) and are described only briefly here. Bundles (4-6 fibres) were dissected and platinum foil clips were attached to the myosepta at the ends of the fibre bundle. The clips were used as stimulating electrodes. At $12^{\circ} \mathrm{C}$, the stimulus strength was adjusted to give a maximal twitch response. Brief tetani $(0.2 \mathrm{~s}$ at $35 \mathrm{~Hz})$ at optimum stimulus strength were used to find the fibre length optimum for isometric force development $\left(L_{0}\right)$. In all subsequent trials fibre length remained at $L_{0}$. At each temperature maximal stimulus strength and the stimulus frequency required for a fused tetanus were established. Tetanus duration was adjusted to be sufficient for plateau force to be reached; plateau force is reported. There was a 3-min rest period between tetani, and at least $30 \mathrm{~min}$ between tests at different temperatures.

\section{Permeabilized fibres}

Bundles of 10-20 fibres, with segments of myosepta attached at each end, were dissected from the slices (West et al. 2004). Fibres were permeabilized by $30 \mathrm{~min}$ immersion in ice-cold relaxing solution (Table 1) containing $1 \%$ (vol/vol) Triton X-100. The myosepta were removed and a single fibre segment about $4 \mathrm{~mm}$ in length was obtained from the bundle; aluminium foil T-clips were then attached to the ends of the preparation.

Rabbit permeabilized fibres

New Zealand White rabbits $(>5 \mathrm{~kg}$ ) were sacrificed with an overdose of pentobarbital in accordance with Schedule 1 of the UK Animals (Scientific Procedures) Act 1986. Bundles of fibres (1-2 mm diameter, 4-5 mm length) were dissected from the psoas major and tied in situ to wood applicator sticks to preserve their in vivo length. Fibres were permeabilized with glycerol as described by Thirlwell et al. (1994) and stored at $-20^{\circ} \mathrm{C}$ for up to 6 weeks before use. For each experiment a segment of a single fibre was isolated from the bundle in relaxing solution (Table 1B) at $5^{\circ} \mathrm{C}$. Aluminium foil T-clips were then attached to the ends of the fibre segment.

\section{Experiments on permeabilized fibres}

Force was measured by an AE 801 transducer (SensoNor, Horten, Norway). The fibre was mounted via the T-clips between the force transducer and a fixed hook. Once mounted, the dogfish fibres were treated at $12^{\circ} \mathrm{C}$, and rabbit fibres at $20^{\circ} \mathrm{C}$, for between 30 and $45 \mathrm{~min}$ with $0.5-1.0 \%$ (vol/vol) Triton $\mathrm{X}-100$ in relaxing solution to remove as much as possible of any remaining membrane fragments and sarcoplasmic reticulum ATPase activity. The fibre was returned to relaxing solution and the striation spacing was adjusted to between 2.35 and $2.45 \mu \mathrm{m}$. Striations were photographed through a X40/0.75 w objective lens and measured using custom-designed software. The fibre diameter was measured with an eyepiece graticule (X40/0.75 w objective lens) and fibre segment length with an eyepiece graticule in a stereomicroscope. The dogfish fibres are much larger than the rabbit fibres (cross-sectional areas 24,981 \pm SEM $925 \mu^{2}, n=41$ and 5,646 \pm SEM 295, $n=34$, respectively).

Activation protocol 1: Dogfish fibres at 5, 12, and $20^{\circ} \mathrm{C}$

Fibres were transferred from pre-activating solution to activating solution at $5^{\circ} \mathrm{C}$ for $8 \mathrm{~s}$, then to activating solution at 12 or $20^{\circ} \mathrm{C}$ for $4 \mathrm{~s}$, and finally to relaxing solution at 12 or $20^{\circ} \mathrm{C}$. This protocol was repeated three times on each fibre with the order of the added [Pi] $\left(\mathrm{mmol} \mathrm{l}^{-1}\right)$ being for half of the fibres: 0, 20, 0, and for the other half: 20, 0 and 20. Twenty fibres were tested at 5 and $12^{\circ} \mathrm{C}$. An additional ten fibres were tested at 5 and $20^{\circ} \mathrm{C}$. See Table $1 \mathrm{~A}$ for solutions and Fig. 1 for example records. The average peak force observed in these experiments with 0 added Pi was $285 \pm$ SEM $7.7 \mathrm{kPa}$ ( $n=20$ fibres) when the higher temperature was $12^{\circ} \mathrm{C}$ and $277 \pm \operatorname{SEM} 8.9 \mathrm{kPa}$ ( $n=10$ fibres $)$ for $20^{\circ} \mathrm{C}$. 
Table 1 Solution composition for experiments on permeabilized fibres

\begin{tabular}{lccl}
\hline A. Protocol 1 & Relax & Pre-activ & Activ \\
\hline Free $\mathrm{Ca}^{2+}$ & 0 & 0 & 0.032 \\
Total EGTA & 25 & 0.1 & 25 \\
Total HDTA & 0 & 24.9 & 0 \\
Total added Pi & 0 & 0 & 0 or 20 \\
\hline
\end{tabular}

B. Protocol 2

\begin{tabular}{lcccccc}
\hline & Relax & Pre-rigor & Ca-free rigor & Ca rigor & Activ & Post-activ relax \\
\hline Free $\mathrm{Ca}^{2+}$ & 0 & 0 & 0 & 0.032 & 0.032 & 0 \\
MgATP & 5 & 0.2 & 0 & 0 & 5 & 5 \\
PC & 0 & 0 & 0 & 20 & 20 & 0 \\
Total added Pi & 0 & 0 & 0 & 0 & $0,5,10$ or 20 & 0 \\
BDM & 0 & 10 & 0 & 0 & 0 & 0 \\
CK & 0 & 0 & 0 & 33 & 0 & 0 \\
Apyr & 0 & 200 & 300 & 300 & 300 \\
IS & 200 & & 00 & &
\end{tabular}

Relax, relaxing solution; Post-activ relax, post-activation relaxing; TES, $N$-tris[Hydroxymethyl]ethyl-2-aminoethanesulfonic acid; EGTA, 1,2$\operatorname{Di}\left(2\right.$ aminoethoxy)ethane-NNN $N^{\prime} \mathrm{N}^{\prime}$-tetra-acetic acid; PC, phosphocreatine; HDTA, $N$-(2-Hydroxyethyl) ethylenediamine- $N, N^{\prime}, N^{\prime}$-triacetic acid; BDM, 2,3-butanedione 2-monoxine, tri-sodium salt; CK, creatine phosphokinase; Apyr, apyrase; IS, ionic strength. Concentrations in mmol $1^{-1}$ except $\mathrm{CK}$ and Apyr, which are $\mathrm{U} \mathrm{ml}^{-1}$

Protocol 1: For experiments on dogfish fibres at 5, 12 and $20^{\circ} \mathrm{C}$. All solutions contained (mmol $1^{-1}$ ): $\mathrm{MgATP}_{3.5}$; free $\mathrm{Mg}^{2+} 2.0$, PC 10, glutathione 10, glycerol-2-phosphate $15, \mathrm{CK} 863 \mathrm{U} \mathrm{ml}^{-1}$. pH 7.1. Ionic strength was adjusted to $300 \mathrm{mmol}{ }^{-1}$ with Kpropionate

Protocol 2: For experiments on dogfish fibres at $12^{\circ} \mathrm{C}$. All solutions contained (mmol ${ }^{-1}$ ): free $\mathrm{Mg}^{2+} 2.0$, total EGTA 30, glutathione 10 , TES $60, \mathrm{pH} 7.25$. Ionic strength was adjusted with Kpropionate. For experiments on rabbit fibres at 20 and $35^{\circ} \mathrm{C}$, the solutions were the same as dogfish at $12^{\circ} \mathrm{C}$ except total EGTA 20, PC 10, pH 7.15 at $20^{\circ} \mathrm{C}, \mathrm{pH} 6.96$ at $35^{\circ} \mathrm{C}$, and IS 190

Activation protocol 2. Dogfish fibres at $12^{\circ} \mathrm{C}$, and rabbit fibres at 20 and $35^{\circ} \mathrm{C}$

Fibres were transferred from relaxing solution through the following sequence of solutions: pre-rigor, $\mathrm{Ca}^{2+}$-free rigor, and $\mathrm{Ca}^{2+}$-rigor for about 5 min each. Following this the fibre was transferred to activating solutions with added [Pi] $\left(\mathrm{mmol} \mathrm{l}^{-1}\right)$ 0, 5, 10 and 20 for about $40 \mathrm{~s}$ each and then transferred to post-activation relaxing solution. The order in which the different [Pi] were used was varied between experiments. See Table 1B for solutions and Fig. 2 for example records.

When a fibre was used for a second or third series of activations, it remained in the post-activation relaxing solution for a minimum period of $10 \mathrm{~min}$ before continuing through the sequence: pre-rigor, etc. To minimize expose to $35^{\circ} \mathrm{C}$ where this was the test temperature, the relaxing, pre-rigor and $\mathrm{Ca}^{2+}$-free rigor solutions were at $20^{\circ} \mathrm{C}$.

The force values reported in the Results are based on the difference between the force at the end of the period in each activating solution and that in the post-activation relaxing solution (see Fig. 2). Ranatunga (1994) has shown that $\mathrm{Ca}^{2+}$-independent force can develop at temperatures above $25^{\circ} \mathrm{C}$, but at $35^{\circ} \mathrm{C}$ and the sarcomere lengths used here this force is small $(<5 \%)$ compared to $\mathrm{Ca}^{2+}$-dependent force. To take account of variation between forceproducing capacities of the fibres due to difference in size, each force measurement in a record (for example, each of the four measurements in the record shown in Fig. 2a) was expressed relative to the mean of these four force measurements. The two-way regression analysis of these sizeindependent force values vs $\log _{10}[\mathrm{Pi}]$ and activation order was made for each set of data, dogfish, rabbit at $20^{\circ} \mathrm{C}$, and rabbit at $35^{\circ} \mathrm{C}$. The constants $(i, s$ and $o$ ) in the following equation were adjusted to give a best fit to the force values by minimizing the sum of the squared difference between the observed and calculated $(f)$ force values:

$f=i+\left(s \times \log _{10}[P i]\right)+(o \times n)$

where $\log _{10}[\mathrm{Pi}]$ is the $\log _{10}$ of the $\mathrm{Pi}$ concentration in mmol $\mathrm{l}^{-1}$, and $n$ is the number of the activation, for example, 1, 2, 3 or 4 in the series. The results of the regression are shown in Table 2 and were used to remove the variation in force due to variation in activation number, 

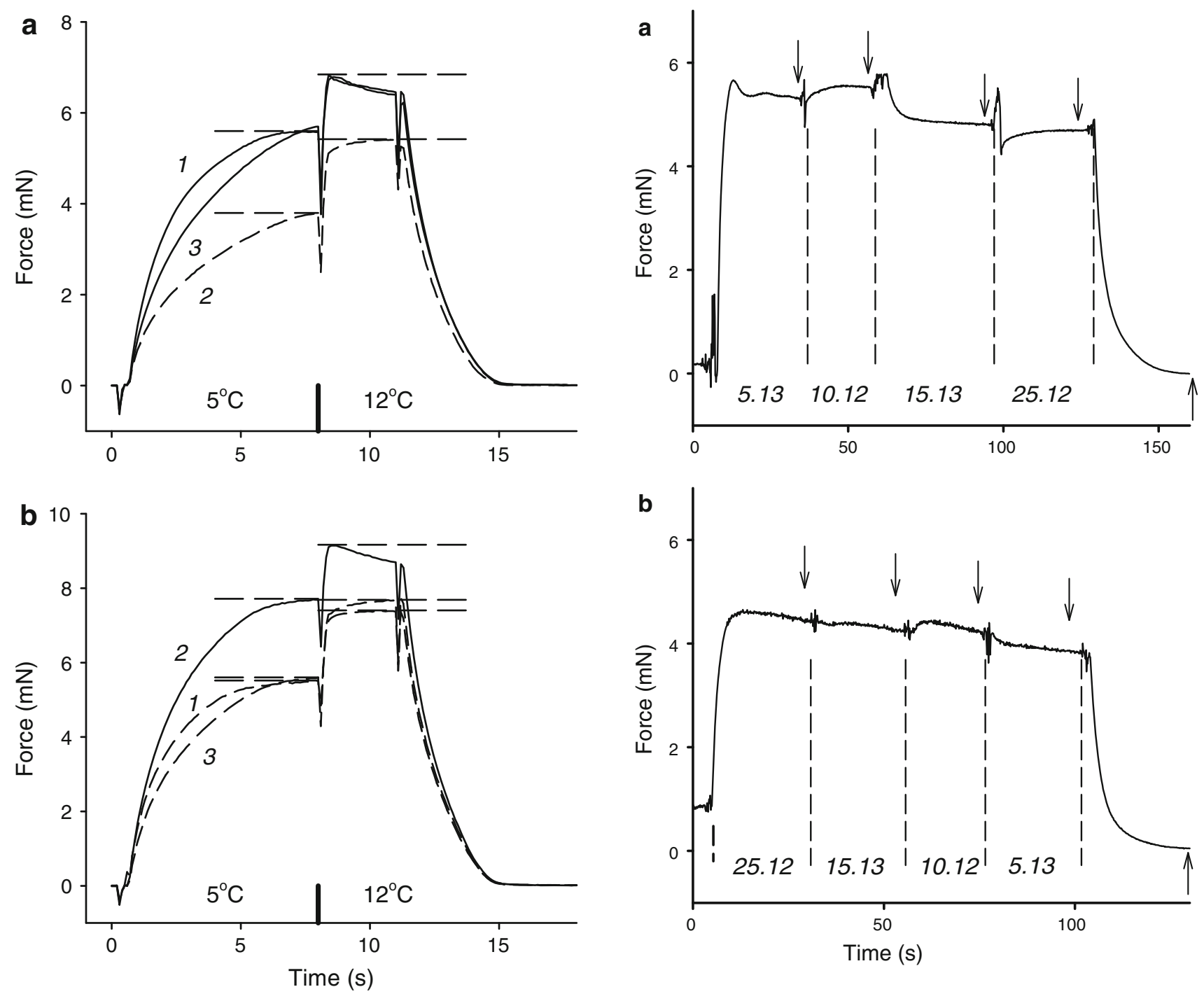

Fig. 1 Superimposed records of force produced by dogfish fibres during activation from relaxed state (activation protocol 1) with temperature change from 5 to $12^{\circ} \mathrm{C}$ after $8 \mathrm{~s}$ of contraction. Records with added $\mathrm{Pi}$ are shown as broken lines. The italic numbers indicate the order of the contractions. a For contraction 1 and $3[\mathrm{Pi}]=$ $2.03 \mathrm{mmol}^{-1}$ at $5^{\circ} \mathrm{C}$ and $2.50 \mathrm{mmol} 1^{-1}$ at $12^{\circ} \mathrm{C}$. For contraction 2 $[\mathrm{Pi}]=22.03 \mathrm{mmol}^{-1}$ at $5^{\circ} \mathrm{C}$ and $22.50 \mathrm{mmol} \mathrm{l}^{-1}$ at $12^{\circ} \mathrm{C}$. b For contraction 1 and 3 [Pi] $22.03 \mathrm{mmol}^{-1}$ at $5^{\circ} \mathrm{C}$ and $22.50 \mathrm{mmol} 1^{-1}$ at $12^{\circ} \mathrm{C}$. For contraction $2[\mathrm{Pi}]=2.03 \mathrm{mmol}^{-1}$ at $5^{\circ} \mathrm{C}$ and $2.50 \mathrm{mmol}^{-1}$ at $12^{\circ} \mathrm{C}$. See text and Tables 3,4 for description of estimation of [Pi]. All records in (a) are from the same fibre. Records in (b) are from a different fibre. Heavy vertical bars mark time at which temperature was changed. Horizontal broken lines show measured values of force

while leaving the effect of variation in [Pi]. In other words, each force value was adjusted to what it would be for activation number $=1$.

The average peak force observed in these experiments was $143 \pm \operatorname{SEM} 14 \mathrm{kPa}(n=18$ fibres$)$ for dogfish fibres at $12^{\circ} \mathrm{C}$ and $185 \pm$ SEM $10 \mathrm{kPa}(n=19$ fibres) for rabbit fibres at $20^{\circ} \mathrm{C}$ and $145 \pm$ SEM $13 \mathrm{kPa}(n=18$ fibres $)$ at $35^{\circ} \mathrm{C}$.

Fig. 2 Example records of force produced by dogfish fibres activated from the rigor state at $12^{\circ} \mathrm{C}$ (activation protocol 2) with (a) increasing and (b) decreasing [Pi]. Italic numbers are the Pi concentrations in units of mmol $\mathrm{l}^{-1}$; broken vertical lines indicate time of solution change. Downward pointing arrows show when force was measured, and the upward pointing arrow shows the baseline from which force was measured. Different fibre in $\mathbf{a}$ than $\mathbf{b}$

\section{Background Pi}

The background $[\mathrm{Pi}]$ is concentration present when no $\mathrm{Pi}$ has been added to the activation solution. It is the sum of Pi contamination and $\mathrm{Pi}$ accumulation due to actomyosin ATPase. See Table 3 for the total background Pi and its components.

\section{Pi contamination}

The free Pi content of phosphocreatine (PC) and of glycerol-2-phosphate (G2P) were assayed using $\mathrm{N}-(2-[1-$ 
maleimidyl]ethyl)-7-diethylamino-coumarin-3 carboxamide phosphate binding protein (MDCC-PBP, West et al. 2004 and references therein). Standard curves were made using dilutions of $\mathrm{KH}_{2} \mathrm{PO}_{4}$. MDCC-PBP fluorescence was measured using a CaSpectrofluorometer (SPEX FluoroMax-3, HORIBA Jobin-Yvon). The results showed that the $\mathrm{Pi}$ contamination in $\mathrm{PC}$ was $5.74 \%$ and in $\mathrm{G} 2 \mathrm{P}$ was $0.694 \%$.

\section{Pi produced during contractions}

In the experiments with permeabilized fibres $\mathrm{Pi}$ is produced by hydrolysis of ATP during contraction and some of it diffuses out of the fibre. We used the diffusion model described in the legend of Table 4 to calculate the net effect of Pi production by ATP hydrolysis in the fibres and Pi diffusion out of the fibres.

Table 2 Regression of force vs. $\log _{10}[\mathrm{Pi}]$ and activation number

\begin{tabular}{llllllllllll}
\hline Preparation & $\mathrm{T}\left({ }^{\circ} \mathrm{C}\right)$ & $i$ & $\pm \mathrm{SE}$ & $P$ & $s$ & $\pm \mathrm{SE}$ & $P$ & $o$ & $\pm \mathrm{SE}$ & $P$ \\
\hline Dogfish & 12 & 1.127 & 0.056 & $<0.001$ & +0.006 & 0.039 & 0.862 & -0.055 & 0.009 & $<0.001$ & 72 \\
Rabbit & 20 & 1.202 & 0.027 & $<0.001$ & -0.155 & 0.023 & $<0.001$ & -0.029 & 0.0093 & $<0.002$ & 74 \\
Rabbit & 35 & 1.205 & 0.030 & $<0.001$ & -0.110 & 0.027 & $<0.001$ & -0.036 & 0.007 & $<0.001$ & 75
\end{tabular}

Force $=i+\left(s \times \log _{10}[\mathrm{Pi}]\right)+(o \times \mathrm{n})$, where force $=$ force/mean force for all activations of that preparation in the same series $($ see Fig. 2). $i=$ intercept; $s=$ slope $=\Delta$ force $/ \Delta \log _{10}[\mathrm{Pi}] ;[\mathrm{Pi}]=$ concentration in $\mathrm{mmol} 1^{-1} ; o=$ slope $=\Delta$ force/ $\Delta$ activation, where activation is the number $(n)$ of the activation, 1, 2, etc., in the series (see Fig. 2). $P$ is the probability for null hypothesis that the intercept or slope value is equal to zero. Degrees of freedom $=d f=$ number of force values -1

Table 3 Background [Pi]

\begin{tabular}{|c|c|c|c|c|c|c|}
\hline \multirow{2}{*}{$\begin{array}{l}\text { Fibre } \\
\text { source }\end{array}$} & \multirow[t]{2}{*}{ Activation protocol } & \multirow{2}{*}{$\begin{array}{l}\mathrm{T} \\
\left({ }^{\circ} \mathrm{C}\right)\end{array}$} & \multicolumn{4}{|c|}{ [Pi] when 0 added $\mathrm{Pi}$} \\
\hline & & & $\begin{array}{l}\text { From PC } \\
\left(\mathrm{mmol}^{-1}\right)\end{array}$ & $\begin{array}{l}\text { From G2P } \\
\left(\mathrm{mmol} \mathrm{1}^{-1}\right)\end{array}$ & $\begin{array}{l}\text { Net from AM-ATPase } \\
\left(\mathrm{mmol} \mathrm{l}^{-1}\right)\end{array}$ & $\begin{array}{l}\text { Total background }[\mathrm{Pi}] \\
\left(\mathrm{mmol} \mathrm{l}^{-1}\right)\end{array}$ \\
\hline Dogfish & 1 & 5 & 0.574 & 0.104 & 1.348 & 2.026 \\
\hline Dogfish & 1 & 12 & 0.574 & 0.104 & 1.818 & 2.496 \\
\hline Dogfish & 1 & 20 & 0.574 & 0.104 & 3.036 & 3.714 \\
\hline Dogfish & 2 & 12 & 1.147 & - & 3.981 & 5.128 \\
\hline Rabbit & 2 & 20 & 0.574 & - & 0.751 & 1.325 \\
\hline Rabbit & 2 & 35 & 0.574 & - & 3.460 & 4.034 \\
\hline
\end{tabular}

Background $\mathrm{Pi}$ is that present in activation solution to which no Pi has been added. Activation protocol 1 and 2 see text for details. $\mathrm{T}$ is temperature. Sources of Pi: PC is phosphocreatine added to activation solution, G2P is glycerol-2-phosphate added to the activation solution, and net AM-ATPase is the net effect of Pi from the actomyosin ATPase and diffusion as described in Table 4. Total background is the sum of Pi from PC, G2P and net AM-ATPase

Table 4 Pi from net effect of actomyosin ATPase and diffusion

\begin{tabular}{|c|c|c|c|c|c|c|}
\hline Fibre source & Activation protocol & $\mathrm{T}\left({ }^{\circ} \mathrm{C}\right)$ & AM-ATPase $\left(\mathrm{s}^{-1}\right)$ & $\mathrm{D}\left(\mu \mathrm{m}^{2} \mathrm{~s}^{-1}\right)$ & {$[\mathrm{Pi}]\left(\mathrm{mmol} \mathrm{1}^{-1}\right)$} & Condition \\
\hline Dogfish & 1 & 5 & $2.4(1)$ & 184.0 & 1.348 & (a) \\
\hline Dogfish & 1 & 12 & $6.0(2)$ & 221.3 & 1.818 & (b) \\
\hline Dogfish & 1 & 20 & $17.3(1)$ & 273.0 & 3.036 & (c) \\
\hline Dogfish & 2 & 12 & $6.0(2)$ & 221.3 & 3.981 & Equilibrium \\
\hline Rabbit & 2 & 20 & $5.9(3)$ & 273.0 & 0.751 & Equilibrium \\
\hline Rabbit & 2 & 35 & $40.3(4)$ & 405.0 & 3.460 & Equilibrium \\
\hline
\end{tabular}

AM-ATPase is rate of Pi production by actomyosin (units: mol Pi. mol myosin ${ }^{-1}$. $\mathrm{s}^{-1}$. Sources (1) calculated from dogfish $12^{\circ} \mathrm{C}$ value using $\mathrm{Q}_{10}$ 3.75, the average from Hill and Woledge (1962) and Homsher and Kean (1978). (2) West et al. (2004). (3) Hilber et al. (2001). (4) Calculated from the rabbit $20^{\circ} \mathrm{C}$ value using $\mathrm{Q}_{10} 3.6$ from Hilber et al. (2001). D is the diffusion coefficient for Pi based on value of $210 \mu \mathrm{m}^{2} \mathrm{~s}^{-1}$ at $10^{\circ} \mathrm{C}$ and $\mathrm{Q}_{10}$ 1.3, from Coupland et al. $(2001)$. [Pi] = net [Pi] due to AM-ATPase and diffusion for conditions: (a) $8 \mathrm{~s} \mathrm{contraction}$ at $5^{\circ} \mathrm{C},(b) 8 \mathrm{~s}$ contraction at $5^{\circ} \mathrm{C}$ followed by $1 \mathrm{~s}$ at $12^{\circ} \mathrm{C},(\mathrm{c}) 8 \mathrm{~s}$ contraction at $5^{\circ} \mathrm{C}$ followed by $1 \mathrm{~s}$ at $20^{\circ} \mathrm{C}$. The diffusion calculation assumes the fibre radius is divided into 40 shells of equal thickness. Fibre radii were: 89.5 and $86.4 \mu \mathrm{m}$ for dogfish used in protocol 1 and 2 , respectively, and $42 \mu \mathrm{m}$ for rabbit 


\section{Results}

Force produced by permeabilized fibres

\section{Activation protocol 1: Activation from resting state}

The example records in Fig. 1 show that force produced by dogfish fibres was influenced by temperature and [Pi]. Force increases abruptly when temperature is increased after $8 \mathrm{~s}$ of activation. Force was less in the solution with added Pi (20 mmol $^{-1}$, broken lines in Fig. 1) than with no added $\mathrm{Pi}$ (full lines). In each experiment there was a repeat test with one of the solutions; the repeat measurements were averaged and then force with $20 \mathrm{mmol} \mathrm{l}^{-1}$ added Pi was expressed relative to force without added Pi. The results from all 30 experiments of this type are summarized in Fig. 3a (open symbols), where the relative force is plotted against the logarithm of the total Pi concentration, that is the background level plus any added Pi (see Methods). The effect of $\mathrm{Pi}$ on force is greater at $5^{\circ} \mathrm{C}$ than at either 12 or $20^{\circ} \mathrm{C}$; the effect is almost the same at the two higher temperatures.

\section{Activation protocol 2: Activation from rigor}

Figure 2 shows example records of force produced by a dogfish fibre during contraction in a series of solutions containing different [Pi]. In Fig. 2a, [Pi] was increased $\left(5.13,10.12,15.13\right.$, and $\left.25.12 \mathrm{mmol} \mathrm{l}^{-1}\right)$ progressively (order number: 1-4). In Fig. 2b, [Pi] was progressively decreased. The records for rabbit fibres were qualitatively similar to those shown in Fig. 2. To examine the effect of [Pi] on force, the relationship of force to both $\log _{10}[\mathrm{Pi}]$ and order number was investigated by two-way regression analysis. The results in Table 2 show that force produced by dogfish fibres did not vary significantly with variations in $\log _{10}[\mathrm{Pi}](P=0.862)$, whereas force did vary inversely with order number $(P<0.001)$. Force produced by rabbit fibres varied inversely with both $\log _{10}$ [Pi] and order number; these relationships were statistically significant at both 20 and $35^{\circ} \mathrm{C}$ (all $P$ values $\leq 0.002$ ). In order to compare the results with those from activation protocol 1 the forces were adjusted to order number $=1$ to remove the effect of variation in the order of presentation of [Pi]. In addition, force was expressed relative to the value with no added Pi. The results are summarized in Fig. 3a, b. Force production by dogfish fibres activated from rigor (activation protocol 2, closed symbols, Fig. 3a) is not affected by increasing [Pi], in contrast to the results for activation from the resting state (activation protocol 1, open symbols). Figure $3 b$ shows that force production by rabbit fibres activated from rigor (black symbols) was depressed by [Pi] at both 20 and $35^{\circ} \mathrm{C}$.
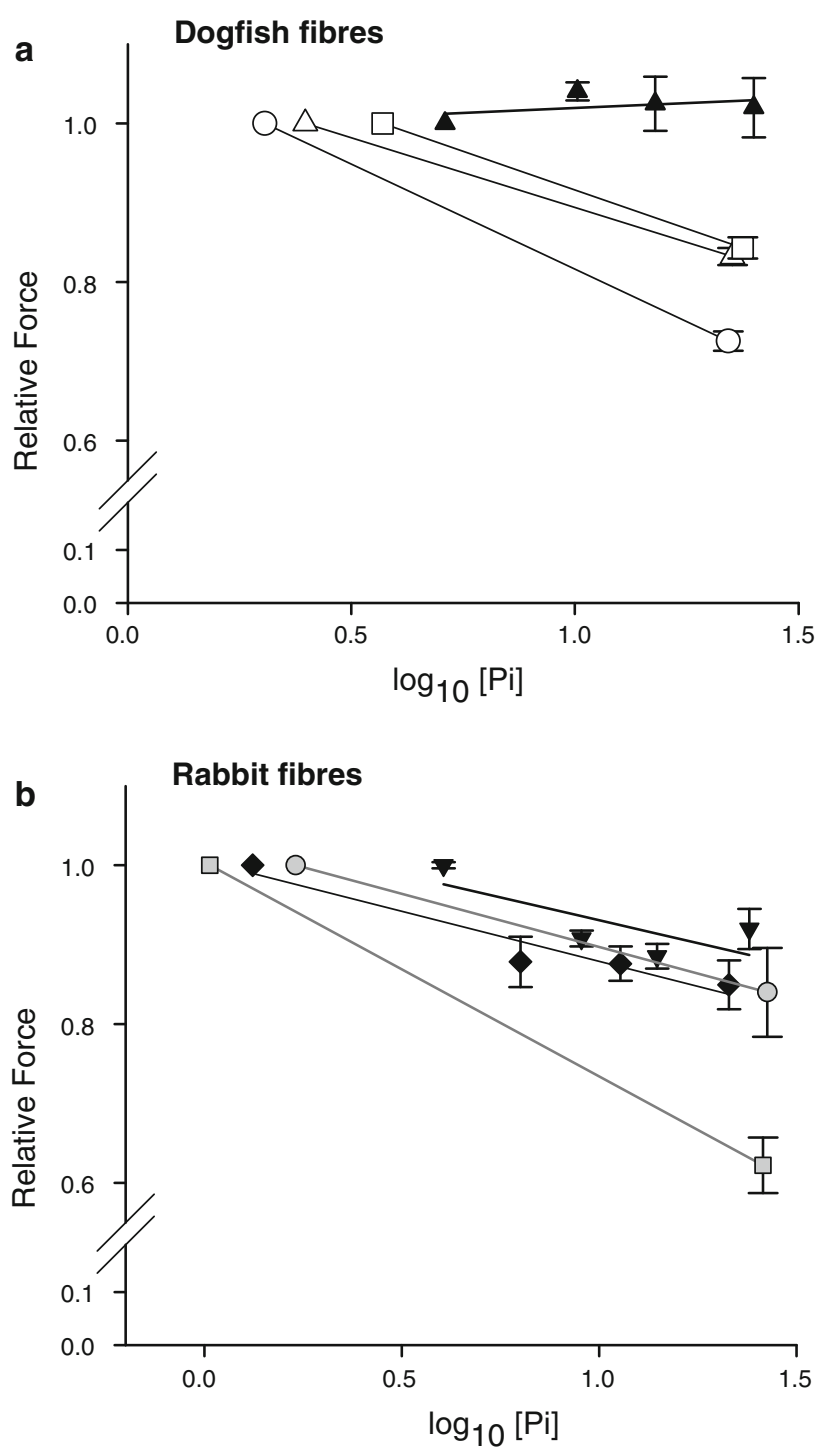

Fig. 3 Summaries of the relationship between relative force and $\log _{10}[\mathrm{Pi}]$ where $[\mathrm{Pi}]$ is in units of mmol $1^{-1}$. Forces were expressed relative to that produced at the lowest $[\mathrm{Pi}]$ to which the fibre was exposed. Mean \pm SEM. a Dogfish fibres. Results for activation from the relaxed state (activation protocol 1): open circles, $5^{\circ} \mathrm{C}(n=30)$; open triangles, $12^{\circ} \mathrm{C}(n=20)$; open squares, $20^{\circ} \mathrm{C}(n=10)$. Activation from rigor (activation protocol 2): closed triangles, $12^{\circ} \mathrm{C}$ $(n=16-18)$. b Rabbit fibres. Activation from rigor (activation protocol 2): closed diamonds, $20^{\circ} \mathrm{C}(n=18)$; closed triangles, $35^{\circ} \mathrm{C}$ ( $n=11-24)$. Rabbit fibre results from Coupland et al. (2001): gray squares, $20^{\circ} \mathrm{C} ;$ gray circles, $35^{\circ} \mathrm{C}$. Regression lines are shown for each set of results

Effect of temperature on force produced by intact fibres from dogfish

Figure 4b (closed symbols) shows force produced by four bundles of intact fibres from dogfish tested in the range $2-20^{\circ} \mathrm{C}$. Temperature strongly influenced force during isometric tetani at $L_{0}$, but the dependence of force on temperature was non-linear. Reducing temperature below 

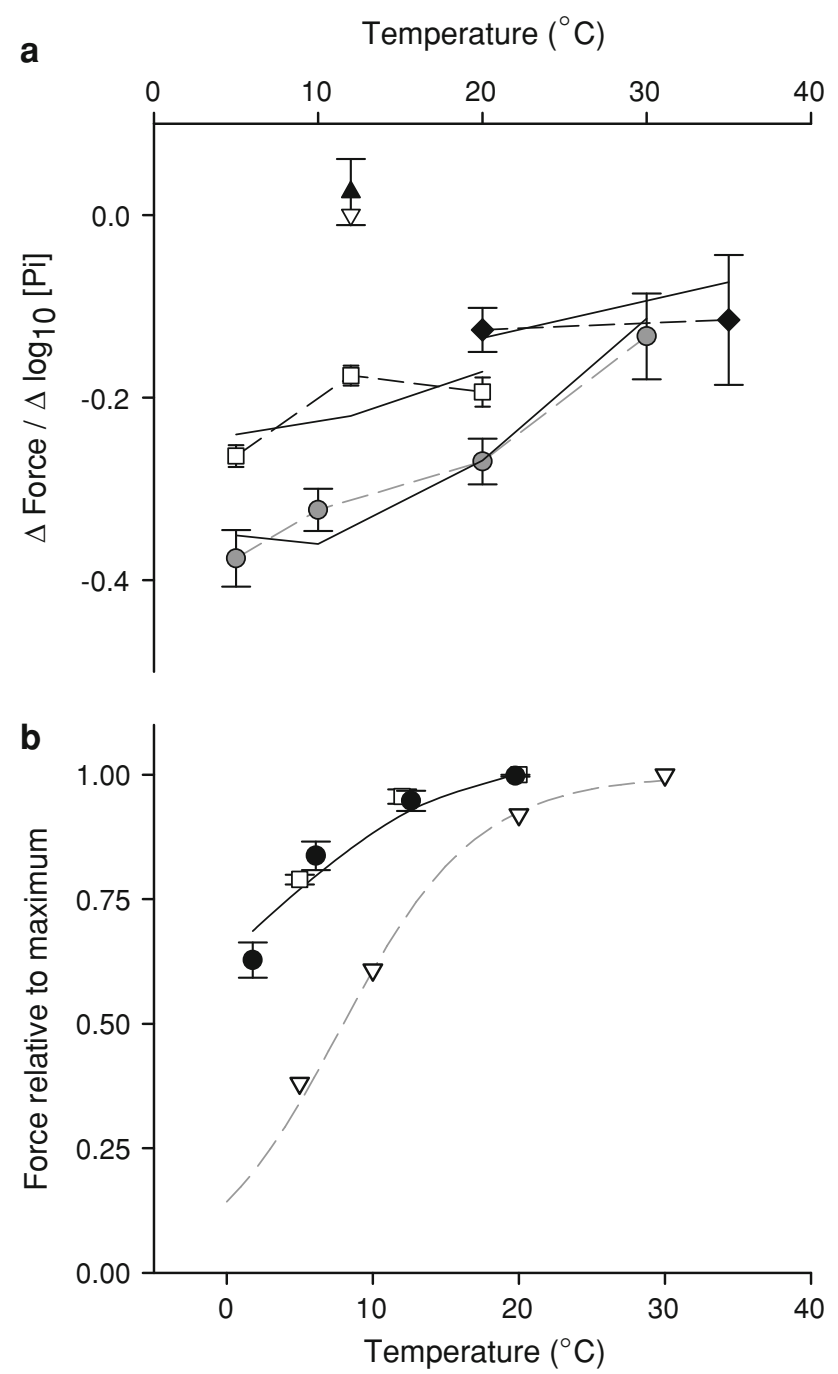

Fig. 4 a Relationship between temperature and Pi sensitivity of force $\left(=\Delta\right.$ Relative force/ $\left.\Delta \log _{10}[\mathrm{Pi}]\right)$. Experimental results shown as mean \pm SE: Dogfish fibres activated from rigor (activation protocol 2), closed triangle; rabbit fibres activated from rigor (activation protocol 2), closed diamonds; dogfish fibres activated from relaxed state (activation protocol 1), open squares. Results from Coupland et al. (2001) for rabbit fibres activated from relaxed state, gray circles. The corresponding model predictions are shown as full lines and open triangle. b Summary of observations of the relationship between relative force and temperature. Relative force $=$ force/maximum force. Coupland et al. (2001) broken gray line summary of observations of force produced by permeabilized rabbit fibres (no added $\mathrm{Pi}$ ); intact fibre bundles from dogfish black closed circles; permeabilized fibres from dogfish activated from relaxed state (activation protocol 1), open squares. Full lines and open triangles are simulations from the model described in the text

$12^{\circ} \mathrm{C}$, the normal body temperature for dogfish, had a larger effect on force than increasing temperature did. Permeabilized dogfish fibres activated from the relaxed state (activation protocol 1) also show the effect of temperature on force. The results are included in Fig. 4b (open squares) and were very similar to those from intact fibres.

\section{Discussion}

Figure 3 shows how Pi influences force produced by dogfish (Fig. 3a) and rabbit (Fig. 3b) fibres. The dogfish fibres when activated from the relaxed state (activation protocol 1 , open symbols) showed a clear sensitivity to $\mathrm{Pi}$, which is greatest at the lowest temperature tested $\left(5^{\circ} \mathrm{C}\right)$. However, when dogfish fibres were activated from rigor (activation protocol 2, closed symbols Fig. 3a) force is insensitive to [Pi], which is clearly different from the rabbit results obtained with the same activation protocol (closed symbols Fig. 3b). For comparison some of the results of Coupland et al. (2001) for rabbit fibres have been added to Fig 3b. In our experiments the effect of Pi on force is less than found by Coupland et al. (2001). The differences are likely to be due to the state of the fibre when activation was initiated because in our activation protocol 2 experiments the fibres were activated from rigor, whereas Coupland et al. (2001) activated their fibres from the relaxed state.

Our results for the rabbit fibres agree with the numerous reports that skinned fibres from many animal species produce less force the higher the [Pi]; for example, rabbit (Brandt et al. 1982; Brozovich et al. 1988; Godt and Nosek 1989; Pate and Cooke 1989; Millar and Homsher 1990; Dantzig et al. 1992; Potma et al. 1995; Potma and Stienen 1996; Pate et al. 1998; Coupland et al. 2001; Caremani et al. 2008), rat (Fryer et al. 1995; Debold et al. 2006), frog (Brozovich et al. 1988; Stienen et al. 1990), Xenopus (Stienen et al. 1999), insect: (Ruegg et al. 1971) and references therein. The force $v s$. [Pi] relationship of rabbit (Coupland et al. 2001) and rat (Debold et al. 2006) fibres has been investigated over a range of temperatures up to $30^{\circ} \mathrm{C}$. For both species force produced at maximum $\mathrm{Ca}^{2+}$ activation is most affected by [Pi] at low temperature.

The effects of temperature on the Pi sensitivity of force are shown in Fig. 4a where the slopes of the regression lines from Fig. 3 ( $\Delta$ force/ $\Delta \log [\mathrm{Pi}])$ are plotted against temperature. It is clear that in both species Pi sensitivity is greater in experiments in which the fibres were activated from the relaxed state (open symbols) than when they were activated from rigor (closed symbols). In both species the results using activation from the relaxed state show the greatest Pi sensitivity at the lowest temperature tested. Figure $4 \mathrm{~b}$ shows the effects of temperature on force for dogfish intact fibres (closed symbols) and for permeabilized fibres activated from the relaxed state; dogfish (open squares) and rabbit fibres (gray broken line). For the dogfish there is good agreement between the results for intact and permeabilized fibres. It is clear that the shape of the relation is similar for rabbit and dogfish experiments, but the dogfish results lie to the left of the rabbit results by approximately $10^{\circ} \mathrm{C}$. Correspondingly, the results for Pi sensitivity in the two species (when activated from the relaxed state) would 
be similar if the rabbit results were shifted to the left by $10^{\circ} \mathrm{C}$ (Fig. 4a). These relationships show that force is relatively insensitive to $[\mathrm{Pi}]$ at the physiological temperature of each species (dogfish $12^{\circ} \mathrm{C}$ and rabbit $39^{\circ} \mathrm{C}$ ). At these temperatures, force is high and thus most crossbridges are in the force-producing states, suggesting that crossbridges in the high force state retain the Pi from ATP splitting and are thus insensitive to $[\mathrm{Pi}]$ concentration.

We quantitatively simulated the dependence of force on [Pi] and temperature, extending the qualitative approach used by Coupland et al. (2001). We used the following abbreviated model of the crossbridge cycle, which is similar to that used by Coupland et al. (2001). The model is referred to as "abbreviated" because it includes the minimum states and steps required to simulate our results; there are only three attached states, and only three steps. Step III includes all transitions required to complete the cycle from AM*.ADP to AM.ADP.Pi.

Simulations in both Fig. $4 a$ and $b$ were calculated from the reaction scheme

$\begin{array}{cccc}\text { States } & 1 & 2 & 3 \\ & \rightarrow \text { AM.ADP.Pi } \leftrightarrow & \text { AM*.ADP.Pi } \leftrightarrow & \text { AM*.ADP }+\mathrm{Pi} \rightarrow\end{array}$

Steps (III)

(I)

(II)

(III)

Parameters used to adjust the kinetic model to fit the different data sets are shown in the table below.

\begin{tabular}{lllllc}
\hline & $\begin{array}{l}\text { Activation } \\
\text { protocol }\end{array}$ & $K_{I}$ & $\begin{array}{l}K_{I I} \\
\left(\mathrm{mmol} \mathrm{l}^{-1}\right)\end{array}$ & $\begin{array}{l}\Delta \mathrm{H}_{\mathrm{I}} \\
\left(\mathrm{kJ} \mathrm{mol}^{-1}\right)\end{array}$ & $\begin{array}{l}\Delta \mathrm{H}_{\mathrm{II}} \\
\left(\mathrm{kJ} \mathrm{mol}^{-1}\right)\end{array}$ \\
\hline Rabbit & 1 & 0.92 & 7.67 & 73 & 74 \\
Rabbit & 2 & 1.76 & 1.27 & 52 & 127 \\
Dogfish & 1 & 1.3 & 4.9 & 34 & 35 \\
Dogfish & 2 & 8.2 & 0.13 & 61 & 32 \\
\hline
\end{tabular}

Step I: $k_{-I}=135 \mathrm{~s}^{-1}$ at $20^{\circ} \mathrm{C}$ and has $Q_{10}=2.3 . k_{+I}$ is calculated from $k_{-I}$ and $K_{I}$. The table gives the $K_{I}$ values at $20^{\circ} \mathrm{C}$; values for other temperatures are calculated using the Van't Hoff equation and $\Delta H_{I}$ values in the table.

Step II: $k_{+I I}=1,000 \mathrm{~s}^{-1}$ at $20^{\circ} \mathrm{C}$ and has a $Q_{10}=2.3$; $k_{-I I}$ is calculated from $k_{+I I}$ and $K_{I I}$. The table gives the $K_{I I}$ values at $20^{\circ} \mathrm{C}$; values for other temperatures are calculated using the Van't Hoff equation and $\Delta H_{I I}$ values in the table.

Step III: $k_{+I I I}$ is calculated from the other rate constants and the rate of ATP turnover shown in Table 4.

State 1 is an attached state that produces no force, and states 2 and 3 are attached states that produce high and equal force, similar to various other models (Dantzig et al. 1992; Coupland et al. 2001; Caremani et al. 2008). Step I, the force-producing step, is endothermic. An increase in temperature increases force (Goldman et al. 1987; Bershitsky and Tsaturyan 2002) by altering the force per attached crossbridge, without increasing the proportion of bridges that are attached (Piazzesi et al. 2003). The Pi release step (II) occurs after force has been developed (step I) (Smith and Sleep 2004).

We have modified the model by constraining it to have the rate of ATP turnover and temperature dependence detailed in Table 4. We found that the fit to our results was improved by making step II endothermic as well as step I. As shown in Fig. 4 the model provides a good simulation of the temperature dependence of the Pi sensitivity of force (Fig. 4a, full lines) and the temperature dependence of force in each species (Fig. 4b, full line and open triangles). The simulation used the rate constants given above.

Although this simple model can explain reasonably well the effects of temperature on force and on Pi sensitivity of force it is unlikely to explain some of the other effects of Pi which have been observed. For example, it has been reported (Potma et al. 1995) that the ATPase rate of rabbit skinned fibres is depressed less than force by increase of [Pi]. Also Caremani et al. (2008) have shown that the stiffness of rabbit permeabilized fibres is reduced by $\mathrm{Pi}$ in proportion to force. Caremani et al. present a model, very similar to ours, that can account for the effects of Pi on force and stiffness. However, there is no obvious way in which it can account for the fact that $\mathrm{Pi}$-sensitivity is less at higher temperature. It seems that a more complex kinetic scheme than that proposed by Caremani et al. (2008), or that proposed here, is required to account for the combined effects of Pi and temperature on force, stiffness and ATPase rate. Such a scheme would include an endothermic force-producing step that occurs without a change in the biochemical state of the attached crossbridge, as suggested by Caremani et al. (2008), and by Woledge et al. (2009).

Implications for in vivo function

Our results taken together with those of Coupland et al. (2001) and Debold et al. (2006) suggest that at physiological temperature $\mathrm{Pi}$ accumulation has little effect on force production in skinned fibres when maximally $\mathrm{Ca}^{2+}$ activated. To the extent that this also applies for intact fibres, the results add to the evidence that very little of the reduction in force during fatigue could be explained by the effects of [Pi] acting alone on the crossbridge cycle itself, by causing a shift to low or non-force producing states. "Acting alone" must be noted because other chemical species change along with Pi even in the very brief contractions that are typical of in vivo function of intact fibres. In addition, activation of the crossbridge cycle by $\mathrm{Ca}^{2+}$ is affected by [Pi] (Allen et al. 2008) and thus could reduce force produced by intact fibres, despite having no effect in skinned fibres. 
Acknowledgments The Wellcome Trust supported the work. We thank Dr. Marco Caremani for designing equipment used for activation protocol 1.

Open Access This article is distributed under the terms of the Creative Commons Attribution Noncommercial License which permits any noncommercial use, distribution, and reproduction in any medium, provided the original author(s) and source are credited.

\section{References}

Allen DG, Lamb GD, Westerblad H (2008) Skeletal muscle fatigue: cellular mechanisms. Physiol Rev 88:287-332

Altringham JD, Johnston IA (1985) Effects of phosphate on the contractile properties of fast and slow muscle fibres from an Antarctic fish. J Physiol 368:491-500

Bershitsky SY, Tsaturyan AK (2002) The elementary force generation process probed by temperature and length perturbations in muscle fibres from the rabbit. J Physiol 540:971-988

Brandt PW, Cox RN, Kawai M, Robinson T (1982) Effect of crossbridge kinetics on apparent $\mathrm{Ca} 2+$ sensitivity. J Gen Physiol 79:997-1016

Brozovich FV, Yates LD, Gordon AM (1988) Muscle force and stiffness during activation and relaxation. Implications for the actomyosin ATPase. J Gen Physiol 91:399-420

Caremani M, Dantzig J, Goldman YE, Lombardi V, Linari M (2008) Effect of inorganic phosphate on the force and number of myosin cross-bridges during the isometric contraction of permeabilized muscle fibers from rabbit psoas. Biophys $\mathrm{J}$ 95: $5798-5808$

Cooke R (2007) Modulation of the actomyosin interaction during fatigue of skeletal muscle. Muscle Nerve 36:756-777

Cooke R, Franks K, Luciani GB, Pate E (1988) The inhibition of rabbit skeletal muscle contraction by hydrogen ions and phosphate. J Physiol 395:77-97

Coupland ME, Puchert E, Ranatunga KW (2001) Temperature dependence of active tension in mammalian (rabbit psoas) muscle fibres: effect of inorganic phosphate. J Physiol 536:879-891

Curtin NA, Woledge RC (1991) Efficiency of energy conversion during shortening of muscle fibres from the dogfish Scyliorhinus canicula. J Exp Biol 158:343-353

Curtin NA, Woledge RC (1993a) Efficiency of energy-conversion during sinusoidal movement of red muscle fibers from the dogfish Scyliorhinus canicula. J Exp Biol 185:195-206

Curtin NA, Woledge RC (1993b) Efficiency of energy conversion during sinusoidal movement of white muscle fibres from the dogfish Scyliorhinus canicula. J Exp Biol 183:137-147

Curtin NA, Woledge RC (1996) Power at the expense of efficiency in contraction of white muscle fibres from dogfish Scyliorhinus canicula. J Exp Biol 199:593-601

Curtin NA, Kushmerick MJ, Wiseman RW, Woledge RC (1997) Recovery after contraction of white muscle fibres from the dogfish Scyliorhinus canicula. J Exp Biol 200:1061-1071

Curtin NA, Gardner-Medwin AR, Woledge RC (1998) Predictions of the time course of force and power output by dogfish white muscle fibres during brief tetani. J Exp Biol 201:103-114

Dantzig JA, Goldman YE, Millar NC, Lacktis J, Homsher E (1992) Reversal of the cross-bridge force-generating transition by photogeneration of phosphate in rabbit psoas muscle fibres. J Physiol 451:247-278

Debold EP, Dave H, Fitts RH (2004) Fiber type and temperature dependence of inorganic phosphate: implications for fatigue. Am J Physiol Cell Physiol 287:C673-C681
Debold EP, Romatowski J, Fitts RH (2006) The depressive effect of $\mathrm{Pi}$ on the force-pCa relationship in skinned single muscle fibers is temperature dependent. Am J Physiol Cell Physiol 290:C1041-C1050

Fryer MW, Owen VJ, Lamb GD, Stephenson DG (1995) Effects of creatine phosphate and $\mathrm{P}(\mathrm{i})$ on $\mathrm{Ca} 2+$ movements and tension development in rat skinned skeletal muscle fibres. J Physiol 482(Pt 1):123-140

Godt RE, Nosek TM (1989) Changes of intracellular milieu with fatigue or hypoxia depress contraction of skinned rabbit skeletal and cardiac muscle. J Physiol 412:155-180

Goldman YE, McCray JA, Ranatunga KW (1987) Transient tension changes initiated by laser temperature jumps in rabbit psoas muscle fibres. J Physiol 392:71-95

Hilber K, Sun YB, Irving M (2001) Effects of sarcomere length and temperature on the rate of ATP utilisation by rabbit psoas muscle fibres. J Physiol 531:771-780

Hill AV, Woledge RC (1962) An examination of absolute values in myothermic measurements. J Physiol 162:311-333

Homsher E, Kean CJ (1978) Skeletal muscle energetics and metabolism. Ann Rev Physiol 40:93-131

Lou F, Curtin NA, Woledge RC (1997) The energetic cost of activation of white muscle fibres from the dogfish Scyliorhinus canicula. J Exp Biol 200:495-501

Lou F, Curtin NA, Woledge RC (1998a) Contraction with shortening during stimulation or during relaxation: how do the energetic costs compare? J Mus Res Cell Motil 19:797-802

Lou F, Curtin NA, Woledge RC (1998b) Distinguishing metabolic heat from condensation heat during muscle recovery. J Exp Biol 201:2553-2558

Lou F, Curtin NA, Woledge RC (1998c) Shortening during stimulation vs. during relaxation-how do the costs compare? Mech Work Prod Work Absorpt Muscle 453:545-555

Lou F, Curtin NA, Woledge RC (1999) Elastic energy storage and release in white muscle from dogfish Scyliorhinus canicula. J Exp Biol 202:135-142

Lou F, Van der Laarse WJ, Curtin NA, Woledge RC (2000) Heat production and oxygen consumption during metabolic recovery of white muscle fibres from the dogfish Scyliorhinus canicula. J Exp Biol 203:1201-1210

Lou F, Curtin NA, Woledge RC (2002a) Contractile properties of dogfish red muscle fibres. J Physiol 539:50P-51P

Lou F, Curtin NA, Woledge RC (2002b) Isometric and isovelocity contractile performance of red musle fibres from the dogfish Scyliorhinus canicula. J Exp Biol 205:1585-1595

Millar NC, Homsher E (1990) The effect of phosphate and calcium on force generation in glycerinated rabbit skeletal muscle fibers. A steady-state and transient kinetic study. J Biol Chem 265:2023420240

Pate E, Cooke R (1989) Addition of phosphate to active muscle fibers probes actomyosin states within the powerstroke. Pflugers Arch 414:73-81

Pate E, Franks-Skiba K, Cooke R (1998) Depletion of phosphate in active muscle fibers probes actomyosin states within the powerstroke. Biophys J 74:369-380

Piazzesi G, Reconditi M, Koubassova N, Decostre V, Linari M, Lucii L et al (2003) Temperature dependence of the force-generating process in single fibres from frog skeletal muscle. J Physiol 549:93-106

Potma E, Stienen G (1996) Increase in ATP consumption during shortening in skinned fibres from rabbit psoas muscle: effects of inorganic phosphate. J Physiol 496:1-12

Potma EJ, van Graas IA, Stienen GJ (1995) Influence of inorganic phosphate and $\mathrm{pH}$ on ATP utilization in fast and slow skeletal muscle fibers. Biophys J 69:2580-2589 
Ranatunga KW (1994) Thermal stress and Ca-independent contractile activation in mammalian skeletal muscle fibers at high temperatures. Biophys J 66:1531-1541

Ruegg JC, Schadler M, Steiger GJ, Muller G (1971) Effects of inorganic phosphate on the contractile mechanism. Pflugers Arch 325:359-364

Smith DA, Sleep J (2004) Mechanokinetics of rapid tension recovery in muscle: the Myosin working stroke is followed by a slower release of phosphate. Biophys J 87:442-456

Stienen GJ, Roosemalen MC, Wilson MG, Elzinga G (1990) Depression of force by phosphate in skinned skeletal muscle fibers of the frog. Am J Physiol 259:C349-C357

Stienen GJM, Papp Z, Zaremba R (1999) Influence of inorganic phosphate and $\mathrm{pH}$ on sarcoplasmic reticular ATPase in skinned muscle fibres of Xenopus laevis. J Physiol 518:735-744
Thirlwell H, Corrie JE, Reid GP, Trentham DR, Ferenczi MA (1994) Kinetics of relaxation from rigor of permeabilized fast-twitch skeletal fibers from the rabbit using a novel caged ATP and apyrase. Biophys J 67:2436-2447

West TG, Curtin NA, Ferenczi MA, He ZH, Sun YB, Irving M et al (2004) Actomyosin energy turnover declines while force remains constant during isometric muscle contraction. J Physiol 555: $27-43$

Woledge RC, Barclay CJ, Curtin NA (2009) Temperature change as a probe of muscle crossbridge kinetics: a review and discussion. Proc Biol Sci 276:2685-2695 